\title{
Correction to: Handbook of Quality of Life and Sustainability
}

Javier Martinez, Claudia Andrea Mikkelsen, and Rhonda Phillips

\section{Correction to:}

J. Martinez et al. (eds.), Handbook of Quality of Life and Sustainability, International Handbooks of Quality-of-Life, https://doi.org/10.1007/978-3-030-50540-0

The original version of the book was inadvertently published without incorporating the author's proof corrections mentioned below. The chapter has now been corrected and approved by the author.

- In Figure 13.3, the part figure (c) has been moved from page 269 to 271.

- In Table 20.2, the data in the rows labelled "Employment" and "Income" has been removed. The data used in this table has been adjusted accordingly.

The updated online versions of the chapters can be found at https://doi.org/10.1007/978-3-030-50540-0_13

https://doi.org/10.1007/978-3-030-50540-0_20 